\section{Tests of the Market's Reaction to Federal Funds Rate Target Changes}

\author{
Daniel L. Thornton
}

r or sometime now, the Fed has implemented monetary policy by making discrete adjustments to its target for the federal funds rate. Given that a change in the funds rate target is taken as a change in monetary policy, it is not surprising that the market reacts to actual and perceived changes in the Fed's funds rate target, [ e.g., Cook and Hahn (1989) and Thornton (1996)]. Several interesting hypotheses concerning the market's reaction to target changes deserve closer consideration.

First and foremost, does a target change alter the market's outlook for inflation? It is widely believed that the Fed has been focusing on inflation and has responded to inflation scares [e.g., Goodfriend (1993)]. Hence, many analysts believe that an increase in the funds rate target reflects an increased concern by the Fed about inflation. In this article, I will show how information about the market's expectations on inflation can be extracted from the differential response of shortterm and long-term rates to federal funds rate target changes. I also will investigate the extent to which short-term and longterm rates respond differently to changes in the funds rate target.

In addition, it is sometimes thought that the magnitude of the target adjustment reflects the intensity of the Fed's resolve.
Adjustments to the funds rate target have ranged from a sixteenth of a percentage point to 75 basis points. If the market believes that the size of the target change is an indication of the Fed's policy resolve, then the market's reaction would change with the size of the target change.

In a similar vein, the Fed occasionally changes the discount rate when adjusting the funds rate target. If the market believes that such actions also reflect a greater policy resolve, then the reaction might be larger when the Fed underscores its funds rate action with a discount rate change.

Finally, once it acts, the Fed typically makes additional funds rate adjustments in the same direction. The market has come to expect this behavior, so that successive moves in the same direction are more likely to be anticipated than the first move in a new direction. Hence, it has been suggested that the market's reaction might be larger when Fed policy changes direction, i.e., the Fed lowers its funds rate target after a prolonged period of upward adjustments or vice versa.

The purpose of this paper is to investigate whether the reactions of the short-term and long-term interest rates provide information about the market's expectations for inflation. In addition, the paper investigates whether ( 1 ) the market's reaction varies with the magnitude of target changes, (2) the reaction is larger when accompanied by discount rate changes, and ( 3 ) the reaction is larger when there is a policy reversal.

\section{TARGET CHANGES AND INFLATION EXPECTATIONS}

Regardless of their maturity, all interest rates have both a real and an inflation expectation component. Therefore, a nominal interest rate, i, can be expressed as

$$
\mathrm{i}_{\mathrm{t}}=\mathrm{r}_{\mathrm{t}}+\pi_{\mathrm{t}}^{\mathrm{e}}
$$

where $r$ denotes the real component of the nominal interest rate and $\pi^{\mathrm{e}}$ denotes the 
${ }^{1}$ The reader is cautioned to note that this statement does not mean there is no inflation expectation component for very short-term interest rates, only that it need not change below some horizon.

2 Strictly speaking, this equation applies only to rates on zero coupon bonds expressed in logarithms, see Campbell, Lo, and MacKinlay (1997)

3 From March 1984 through September 1989, the Fed changed its funds rate target 76 times. By contrast, the target was changed just 32 times from October 1989 to December 1997.

${ }^{4}$ The pattern of changing the discount rate only when the funds rate target was changed was initiated under Chairman Greenspan. Other chairman frequently adjusted the discount rate without simultaneously changing the funds rate target.

5 The 3-month and 12-month rates are secondary market rates on treasury securities with these maturities. The long-term rates are constant maturity yields. All rates are taken from the Board of Governors, H.15 Statistical Release. inflation expectation component. Interest rates of all maturities respond to new information about real returns and future inflation. News of a federal funds rate target change may provide information about both. Furthermore, news of a policy change is likely to move the real and inflation expectation components in opposite directions. For example, an increase in the funds rate target is thought to raise the real federal funds rate and, hence, the real component of all rates. Because such an action signals a more restrictive monetary policy, however, it may also cause the market to revise its inflation expectation downward. Consequently, a change in the funds rate target could cause nominal interest rates to rise or fall depending on the relative magnitude of these effects.

Because the effect of a policy action on inflation is not likely to be immediate, a revision of the inflation outlook is likely to have either a small or no effect on shorterterm rates. ${ }^{1}$ Hence, most market analysts believe that short-term rates should move in the same direction as the target change. Because the effect of an inflation outlook change should be larger, the longer the term to maturity, long-term rates could rise, fall or be unchanged-depending on whether the revision to the inflation outlook was smaller, larger, or exactly equal to the change in the real rate.

The above analysis suggests that one can determine whether target changes caused the market to revise its inflation outlook by investigating the differential response of short-term and long-term rates. It is not quite this simple, however. Long-term rates may not respond significantly to target changes even if individuals do not revise their inflation outlook. Many economists believe that long-term rates are related to shortterm rates according to the expectations theory of the term structure of interest rates. The expectations theory states that the long-term rate is equal to the market's current expectation for the short-term rate plus a constant risk premium. ${ }^{2}$

If the expectations theory holds, a rise in the short-term rate- that is expected to last for the term of the long-term bond, or longer - will increase the long-term rate by the same amount. If the expectations theory holds and if policy actions have only a temporary effect on the real rate, the effect of a target change on long-term rates will be smaller, the longer the term to maturity. For example, let us assume that the expectations theory holds and the Fed raises the funds rate target from 5 to 5.5 percent, but the market expects the Fed to reduce the target back to 5 percent after a year. The one-year rate would rise by the entire 50 basis points; however, the 10 year rate would increase by only five basis points and the 30-year rate by less than two basis points. Because of this possibility, finding that long-term rates respond little to changes in the funds rate target does not necessarily imply that the market has revised its expectation for inflation. It may simply indicate that the change in the real rate is expected to be temporary.

\section{THE MARKET'S REACTION TO TARGET CHANGES}

The analysis presented here covers the period from October 2, 1989, through December 31, 1997. Since late 1989, the Fed has adjusted its funds rate target by at least 25 basis points and funds rate adjustments have been less frequent. ${ }^{3}$ Prior to that, adjustments were as small as a sixteenth, i.e., 6.25 basis points.

During the sample period the Fed made 32 adjustments to its funds rate target. Of these, seven were greater than 25 basis points in absolute value; the rest were 25 basispoint changes. On 12 occasions the Fed simultaneously changed the discount rate, and there was no instance when the discount rate was changed without changing the funds rate target. ${ }^{4}$ All of the seven target changes greater than 25 basis points were accompanied by a discount rate change.

Four market interest rates are used in this analysis: the rates on 3-month, 12month, 10-year, and 30-year Treasury securities, denoted T 3m, T12m, T 10y, and T30y, respectively. ${ }^{5}$ The Federal Reserve Bank of N ew York provided the Fed's federal funds rate target, fftar. 
The market's reaction to changes in the funds rate target is investigated by estimating the equation

$$
\Delta \mathrm{i}_{\mathrm{t}}=\gamma+\beta \Delta \mathrm{fftar}_{\mathrm{t}}+\varepsilon_{\mathrm{t}},
$$

where $i$ denotes one of the four Treasury rates. ${ }^{6}$ The coefficient $\beta$ measures the market's response to the unanticipated portion of the target change. ${ }^{7}$ Estimates of Equation 1 using the four interest rates are presented in Table 1. Both short-term rates respond significantly to changes in the funds rate target. The reactions of the long-term rates are much smaller and neither response is statistically significant.

Is the statistically insignificant response of the long-term rates because the market has changed its inflation outlook or because the market believes that the change in the real rate is temporary? Answering this question is difficult. If the lack of a response is because the change in the real rate is expected to be temporary, however, the reaction of longterm rates should always be small. If it is because of inflation expectations, long-term rates might rise sometimes and fall at others. In the latter case, the absolute change in long-term rates should be larger on days when the Fed changes the funds rate target than on other days.

The mean and median of the absolute change in T10y and T30y on target-change days were .077 and .060 , and .066 and .060 , respectively. The mean and median of absolute changes on other days were 042 and .030 , and .037 and .030 , respectively. Are the means and medians larger on target change days than on non-target change days? Because the absolute value is bounded by zero, the usual difference tests cannot be used to test the null hypotheses that the means and medians on target-change days and other days are equal. Hence, the critical values for these hypotheses were determined by bootstrapping 10,000 samples, size 32 , for both rates from the 2,043 days when there was no change in the target. The 1 percent critical values for the mean of T10y and T30y are .0597 and .0538, respectively. The 1 percent critical value for the median

\section{Table 1}

The Market's Response to Federal Funds Rate Target Changes

\begin{tabular}{|c|c|c|c|c|}
\hline Coefficient & T3m & $\mathrm{T} 12 \mathrm{~m}$ & T10y & T30y \\
\hline \multirow[t]{2}{*}{$\gamma$} & -0.0008 & -0.0008 & -0.0011 & -0.0011 \\
\hline & $(0.92)$ & $(0.81)$ & $(0.89)$ & $(0.96)$ \\
\hline \multirow[t]{2}{*}{$\beta$} & $0.3082 *$ & $0.2599 *$ & 0.0693 & 0.0342 \\
\hline & $(6.11)$ & $(3.99)$ & $(1.24)$ & $(0.70)$ \\
\hline s.e. & 0.0407 & 0.0472 & 0.0577 & 0.0513 \\
\hline Adj. $R^{2}$ & 0.0905 & 0.0499 & 0.0020 & 0.0003 \\
\hline
\end{tabular}

\section{Table 2}

Correlations Between Changes in Rates

\begin{tabular}{|c|c|c|c|c|}
\hline & $\mathrm{T} 3 \mathrm{~m}$ & $\mathrm{~T} 12 \mathrm{~m}$ & T10y & T30y \\
\hline T3m & 1.000 & 0.667 & 0.407 & 0.345 \\
\hline $\mathrm{T} 12 \mathrm{~m}$ & - & 1.000 & 0.758 & 0.672 \\
\hline T10y & - & - & 1.000 & 0.944 \\
\hline T30y & - & - & - & 1.000 \\
\hline
\end{tabular}

of both rates was .05. Because the means and medians on target change days are larger than these values, the null hypotheses of equality is rejected at the 1 percent significance level in every case.

\section{When Is No Significant Response a Significant Response?}

When is no response a significant response? The answer is when no response is different than would have otherwise occurred. On the average, these interest rates tend to move together. This is illustrated in Table 2, which presents the correlation between changes in the four rates. While the correlation tends to be higher for adjacent maturities, the correlation between $\Delta \mathrm{T} 3 \mathrm{~m}$ and $\Delta \mathrm{T} 30 \mathrm{y}$ is statistically significant. The correlation between $\Delta \mathrm{T} 3 \mathrm{~m}$ and $\Delta \mathrm{T} 10 \mathrm{y}$
${ }^{6}$ The equations were estimated using the Newey-West (1987) heteroskedastic autocorrelation consistent estimate of the variances.

${ }^{7}$ If the target change were completely anticipated, the rate would not respond to target changes, i.e., $\beta=0$. Hence, finding that $\beta=0$ for all rates would not necessarily imply that the market did not respond to target changes, but merely that the changes were anticipated. Robertson and Thornton (1997) show that funds rate target changes appear to be difficult to predict, which suggests that part of any change is likely to be unanticipated. 


\begin{tabular}{|c|c|c|c|}
\hline \multicolumn{4}{|c|}{$\begin{array}{l}\text { Longer-Term Rates Response } \\
\text { to Federal Funds Rate Target } \\
\text { Changes }\end{array}$} \\
\hline Coefficient & $\mathrm{T} 12 \mathrm{~m}$ & T10y & T30y \\
\hline$\gamma$ & $\begin{array}{c}-0.0003 \\
(0.34)\end{array}$ & $\begin{array}{c}-0.0007 \\
(0.58)\end{array}$ & $\begin{array}{c}-0.0007 \\
(0.68)\end{array}$ \\
\hline$\delta$ & $\begin{array}{c}0.7476^{*} \\
(18.28)\end{array}$ & $\begin{array}{c}0.5829 * \\
(12.49)\end{array}$ & $\begin{array}{c}0.4451 * \\
(11.21)\end{array}$ \\
\hline$\mu$ & $\begin{array}{l}0.0295 \\
(0.72)\end{array}$ & $\begin{array}{c}-0.1104 * \\
(2.42)\end{array}$ & $\begin{array}{c}-0.1030 * \\
(2.49)\end{array}$ \\
\hline s.e. & 0.0360 & 0.0526 & 0.0480 \\
\hline Adj. $R^{2}$ & 0.4451 & 0.1704 & 0.1245 \\
\hline
\end{tabular}

and $\Delta \mathrm{T} 30 \mathrm{y}$ suggests that there is a tendency for long-term rates to move with the T-bill rate. Hence, the lack of a significant response of T10y and T30y to target changes is a marked departure from the usual relationship between the long-term rates and the T-bill rate.

This can be demonstrated more clearly by estimating the equation

$$
\Delta i_{t}=\gamma+\delta \Delta \mathrm{T} 3 m_{t}+\mu \Delta f \operatorname{ftar}_{t}+\varepsilon_{\mathrm{t}}
$$

${ }^{8}$ For example, see Shiller, Campbell, and Schoenholtz (1983), and Campbell and Shiller (1991). Empirical support of the idea that short-term Treasury rates are equal to the market's expectation for the ovemight federal funds rate is particularly scant, see Thomton (1998).

${ }^{9}$ Market participants do not shift from one end of the market to the other in response to changes in rate differentials, even if the rate at the long end of the market is inconsistent with their own expectation for the future behavior of shortterm rates. where $\Delta \mathrm{i}_{t}$ denotes the change in one of the three other rates. The coefficient $\delta$ measures the "usual" association between $\Delta \mathrm{i}_{\mathrm{t}}$ and $\Delta \mathrm{T} 3 \mathrm{~m}_{\mathrm{t}}$, and $\mu$ measures the deviation from this relationship per unit change in the funds rate target.

Estimates of Equation 2 are presented in Table 3. Note that the estimated reaction of T30y to funds rate target changes in Table 1 is identical to that obtained from Table 3, given the estimated usual relationship between $\Delta \mathrm{T} 3 \mathrm{~m}$ and $\Delta \mathrm{T} 30 \mathrm{y}$ and the estimate of $\mu$. For example, the estimate of $\beta$ from Equation 1 indicates that T3m changed 3082 percentage points for every one-percentage point change in the funds rate target. The estimate of $\delta$ from Equation 2 indicates that T30y usually changes by .4451 for any one-percentage point change in $\mathrm{T} 3 \mathrm{~m}$. If the usual relationship were maintained, T30y would have changed by 13.72 basis points $[(0.3082)(0.4451) 100]$. The estimate of $\mu$ indicates the $T 30 \mathrm{y}$ changes by 10.30 basis points less than normal when the funds rate target was changed, however. Consequently, the T30y increased by only 3.42 basis points [ $13.72-10.30]$, which is the estimated response of T30y to a onepercentage point change in the funds rate target reported in Table 1. Likewise, analogous calculations reveal that the estimated responses of $\mathrm{T} 12 \mathrm{~m}$ and T10y obtained from Table 3 are nearly identical to those reported in Table 1.

While the estimated response of the long-term rates to a target change is the same from both specifications, the interpretations differ. The lack of a significant change in the 10- and 30-year rates to a change in the funds rate target is now seen as a statistically significant departure from what usually would happen given the change in the 3-month rate.

The significant departure from the usual relationship between short-term and longterm rates associated with changes in the funds rate target tends to suggest that target changes affect the market's expectation for inflation. If not, why would changes in T 3m (associated with target changes) be less permanent than other changes?

Though prevalent in monetary policy analyses [e.g., Cook and Hahn (1989) and Goodfriend (1991)], empirical support for the expectations theory is scant. ${ }^{8}$ Hence, interpreting these results in terms of the expectations theory, as was just done, may be unwise. The alternative segmented markets hypothesis asserts that individuals have a preference to borrow or lend in one end of the market. ${ }^{9}$ Because of this hypothesis, as well as uncertainty, the long-term rate is not necessarily equal to the average of the market's expectation for the short-term rate, even when the risk premium is zero.

If the segmented markets hypothesis holds, a shock at one end of the market is reflected in the other, but to different degrees. Consequently, the relationship between long-term and short-term rates reflects the 
usual degree of arbitrage between these ends of the market. Alternatively, it could reflect the differential response of both markets to the same shock - a change in the funds rate target. The fact that the market responds differently to policy shocks suggests that they have different implications for those markets. An important difference is their implication for the future course of inflation.

The significant difference in the usual relationship between long-term and T-bill rates associated with changes in the funds rate target tends to support the interpretation that target changes affect the market's inflation outlook. Ideally, a direct connection between inflation expectations and changes in the funds rate target would verify this interpretation. This connection is not possible, however, because daily measures of the market's inflation expectation, which have been available only recently, are insufficient to test the hypothesis directly. ${ }^{10}$ Evidence of the market's reaction to employment reports tends to support this interpretation, however. Long-term rates respond as much (or more than) short-term rates to employment surprises. Presumably this is because employment surprises generate expectations of a permanent change in the real rate. If changes in the funds rate produced equally permanent changes in the real rate, the smaller response of long-term rates to target changes would appear to be because the market revises its inflation outlook.

\section{DOES THE REACTION VARY WITH THE SIZE OF THE ACTION?}

To test whether the market's reaction varies with the size of the Fed's action, the equation

$$
\begin{aligned}
\Delta \mathrm{i}_{\mathrm{t}} & =\gamma+\delta \Delta \mathrm{T} 3 \mathrm{~m}_{\mathrm{t}} \\
& +\mu_{\mathrm{lg}} \Delta \mathrm{fftar} r_{\mathrm{t}}^{\mathrm{lg}} \\
& +\mu_{\mathrm{sm}} \Delta \mathrm{fftar}_{\mathrm{t}}^{\mathrm{sm}} \\
& +\varepsilon_{\mathrm{t}}
\end{aligned}
$$

was estimated, where target changes are partitioned into large, $\Delta \mathrm{fftar}_{\mathrm{t}}^{\mathrm{lg}}$ and small

\section{Table 4}

\begin{tabular}{|c|c|c|c|c|}
\hline Coefficient & $\mathrm{T} 3 \mathrm{~m}$ & $\mathrm{~T} 12 \mathrm{~m}$ & T10y & T30y \\
\hline$\gamma$ & $\begin{array}{c}-0.0008 \\
(0.89)\end{array}$ & $\begin{array}{l}-0.0001 \\
(0.16)\end{array}$ & $\begin{array}{l}-0.0006 \\
(0.50)\end{array}$ & $\begin{array}{l}-0.0006 \\
(0.60)\end{array}$ \\
\hline$\delta$ & - & $\begin{array}{c}0.7471^{*} \\
(18.27)\end{array}$ & $\begin{array}{c}0.5826^{*} \\
(12.49)\end{array}$ & $\begin{array}{c}0.4448^{*} \\
(11.20)\end{array}$ \\
\hline$\mu_{\mathrm{lg}}$ & $\begin{array}{l}0.3009 * \\
(3.91)\end{array}$ & $\begin{array}{c}-0.0148 \\
(0.25)\end{array}$ & $\begin{array}{l}-0.1410^{*} \\
(2.14)\end{array}$ & $\begin{array}{c}-0.1311^{*} \\
(2.17)\end{array}$ \\
\hline$\mu_{\mathrm{sm}}$ & $\begin{array}{l}0.3179 * \\
(5.61)\end{array}$ & $\begin{array}{l}0.0886 * \\
(2.42)\end{array}$ & $\begin{array}{c}-0.0696 \\
(1.30)\end{array}$ & $\begin{array}{c}-0.0656 \\
(1.38)\end{array}$ \\
\hline $\begin{array}{l}\text { F-statistic } \\
\mu_{\mathrm{sm}}=\mu_{\mathrm{lg}}\end{array}$ & 0.0318 & 2.2845 & 0.7433 & 0.7576 \\
\hline s.e. & 0.0407 & 0.0360 & 0.0526 & 0.0480 \\
\hline Adj. $R^{2}$ & 0.0902 & 0.4468 & 0.1706 & 0.1248 \\
\hline
\end{tabular}

The Market's Response to Federal Funds Rate Target Changes by the Size of the Target Change

changes, $\Delta \mathrm{fftar}_{\mathrm{t}}^{\mathrm{sm}}$. Here, and in all subsequent estimates, when the $i^{\text {th }}$ rate is $T 3 \mathrm{~m}, \delta$ is set to zero. A large change is more than 25 basis points in absolute value, while a small change is exactly 25 basis points. Only seven of the 32 target changes were large. There was one 75 basis point change and six 50 basis point changes.

Estimates of Equation 3 are presented in Table 4. The reaction of T $3 \mathrm{~m}$ is the same regardless of the target change. Hence, the size of the change does not appear to make a difference at the short-end of the market. The reaction at the longer-end of the market is different, however. Specifically, the reaction of T12m is larger for small changes in the funds rate target and smaller for large target changes. This difference is not statistically significant, however. The absolute value of the response for T10y and T30y is greater for larger target changes. These results suggest that the market believes that large policy actions will have a greater
${ }^{10}$ The Treasury began issuing 10-year Treasury Inflation Protected Securities (TIPS) in January 1997 and 30-year TIPS in April 1998. 


\section{Figure 1}

Federal Funds Rate, Funds Rate Target, and Discount Rate

(October 2, 1989 - December 31, 1997)

Percent

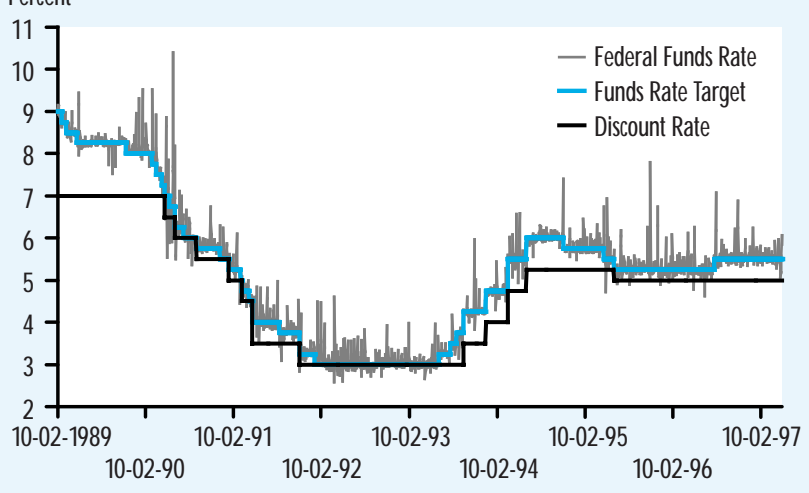

11 It could be that the Trading Desk of the Federal Reserve Bank of New York has done a good job signaling its intentions. See Feinman (1993) and Muelendyke (1998) for discussions of how the Desk signals its intentions to the market.

${ }^{12}$ None of the 12 discount rate changes were made solely to realign the discount rate. effect on inflation; however, the difference in the reaction is not statistically significant for these rates either. Because all seven large funds rate target changes were accompanied by a change in the discount rate, it is impossible to determine whether the difference is due to the size of the change or to the discount rate change.

\section{IS THE MARKET'S REACTION LARGER WHEN ACCOMPANIED BY A DISCOUNT RATE CHANGE?}

Before investigating whether the market's response is affected by a discount rate change, it is important to ask: Why would the Fed be more likely to change the discount rate when it makes relatively large adjustments in its funds rate target? One possibility is that the Fed wants the market to know it is taking action. This explanation does not seem likely because most often a discount rate change accompanies large target changes. The market should have a much easier time identifying large target changes than small ones. Moreover, since the fall of 1989, it appears that the market has had little difficulty identifying target changes whether the Fed announced them with a discount rate change or not. ${ }^{11}$
Another possibility is that the Fed adjusts the discount rate when it changes the funds rate target because failure to do so would cause the spread between the two rates to become either too wide or too narrow. Figure 1, which shows the federal funds rate, the discount rate, and the funds rate target over this period, suggests that the Board of Governors of the Federal Reserve did not cut the discount rate until the point was reached where further cuts would have caused the spread between the federal funds rate target and the discount rate to become negative. Indeed, this was the case for each of the first seven discount rate cuts. On two of these occasions, however, maintaining the alignment between the discount rate and the federal funds rate was not one of the reasons the Fed gave for reducing the discount rate. Furthermore, on none of these occasions was this the sole reason given for changing the discount rate.

Furthermore, the need to make a technical adjustment was not given as a reason for any of the four discount rate increases. ${ }^{12}$ Hence, it appears that the discount rate changes (made when interest rates were rising) were not made to prevent the spread from becoming too large. This is not surprising since, historically, the Fed has tolerated a spread of 300 basis points or more.

It could be that the Fed made large changes in the target to emphasize its resolve, which it underscored by simultaneously changing the discount rate. This interpretation is consistent with the fact that all seven large target changes were accompanied by a discount rate change. Of course, the discount rate could have changed out of concern for the size of the spread as well as to underscore the Fed's policy resolve.

To test whether the market's reaction depends on whether the discount rate is changed, the equation

$$
\begin{aligned}
\Delta \mathrm{i}_{\mathrm{t}} & =\gamma+\delta \Delta \mathrm{T} 3 \mathrm{~m}_{\mathrm{t}} \\
& +\mu_{\Delta d r} \Delta \mathrm{fftar}_{\mathrm{t}}^{\Delta \mathrm{dr}} \\
& +\mu_{\mathrm{n} \Delta \mathrm{dr}} \Delta \mathrm{fftar}_{\mathrm{t}}^{\mathrm{nddr}} \\
& +\varepsilon_{\mathrm{t}}
\end{aligned}
$$


is estimated. Target changes are partitioned into those accompanied by a discount rate change, $\Delta \mathrm{fftar}_{\mathrm{t}}^{\Delta \mathrm{dr}}$ and those not accompanied by a discount rate change, $\Delta \mathrm{fttar}_{\mathrm{t}}^{\mathrm{n} \Delta \mathrm{dr}}$. Twelve of the 32 target changes during this period were accompanied by a discount rate change. On the last six of these occasions, the target change equaled the discount rate change. On five of the previous six occasions, the target change was exactly half of the discount rate change.

The results are presented in Table 5. Given that the seven large target changes were accompanied by a discount rate change, it is not surprising that these results are very similar to the results of large and small target changes. The fact that the $T 3 \mathrm{~m}$ does not respond differently when the Fed changes the discount rate is consistent with my previous finding, Thornton (1996).

Because seven of the 12 discount rate changes coincide with large target changes, it is difficult to determine whether the response is larger because the Fed changed the discount rate or because the Fed made a large change in the funds rate target. To separate the discount rate effect from the size effect, the 12 target changes associated with discount rate changes are partitioned into the seven large changes, $\Delta \mathrm{fftar}_{\mathrm{t}}{ }_{\mathrm{tr}} \mathrm{gg}$, and the five small ones, $\Delta \mathrm{fftar}_{\mathrm{t}}^{\Delta \mathrm{drsm}}$. The results, summarized in Table 6, suggest that it is the discount rate change, not the size of the target change, that matters for the behavior of long-term rates. Again, the response of the 3-month T-bill rate is essentially the same whether the discount rate is changed or not, or whether the target change is large or small. The effect on longer-term rates depends on the discount rate. This is particularly true for the 10- and 30-year rates, where the effect of a target change is much smaller if accompanied by a change in the discount rate.

If the reason that long-term rates respond differently to target changes is because the market revises its outlook for inflation, then the results in Table 6 suggest that this effect is associated with the 12 occasions when the Fed simultane-
Table 5

The Market's Response to Federal Funds Rate Target Changes Accompanied by Discount Rate Changes

\begin{tabular}{|c|c|c|c|c|}
\hline Coefficient & T3m & $\mathrm{T} 12 \mathrm{~m}$ & T10y & T30y \\
\hline$\gamma$ & $\begin{array}{c}-0.0008 \\
(0.92)\end{array}$ & $\begin{array}{c}-0.0002 \\
(0.23)\end{array}$ & $\begin{array}{c}-0.0006 \\
(0.53)\end{array}$ & $\begin{array}{c}-0.0006 \\
(0.61)\end{array}$ \\
\hline$\delta$ & - & $\begin{array}{c}0.7476^{*} \\
(18.28)\end{array}$ & $\begin{array}{c}0.5829 * \\
(12.49)\end{array}$ & $\begin{array}{c}0.4452^{*} \\
(11.20)\end{array}$ \\
\hline$\mu_{\Delta \mathrm{dr}}$ & $\begin{array}{l}0.3093 * \\
(4.56)\end{array}$ & $\begin{array}{c}-0.0030 \\
(0.06)\end{array}$ & $\begin{array}{c}-0.1374^{*} \\
(2.36)\end{array}$ & $\begin{array}{c}-0.1337^{*} \\
(2.50)\end{array}$ \\
\hline$\mu_{\mathrm{n} \Delta \mathrm{dr}}$ & $\begin{array}{l}0.3061 * \\
(4.34)\end{array}$ & $\begin{array}{l}0.0913^{*} \\
(2.23)\end{array}$ & $\begin{array}{c}-0.0590 \\
(0.90)\end{array}$ & $\begin{array}{c}-0.0446 \\
(0.79)\end{array}$ \\
\hline $\begin{array}{c}\text { F-statistic } \\
\mu_{\Delta \mathrm{dr}}=\mu_{\mathrm{n} \Delta \mathrm{dr}}\end{array}$ & 0.0010 & 2.0636 & 0.8342 & 1.3585 \\
\hline s.e. & 0.0407 & 0.0360 & 0.0526 & 0.0480 \\
\hline Adj. $R^{2}$ & 0.0901 & 0.4464 & 0.1707 & 0.1253 \\
\hline
\end{tabular}

ously changed the discount rate. When target changes are not accompanied by a discount rate change, the response is only slightly smaller and not statistically significant from the usual relationship with the T-bill rate.

\section{IS THE MARKET'S REAC TION LARGER WHEN THERE IS A CHANGE IN THE DIRECTION OF POLICY?}

The question of whether the market's reaction is different when the Fed changes the direction of policy is difficult to address because there were only three changes in policy direction during the sample period. The first 21 target changes were negative for a total of 600 basis points. M oreover, extending the sample backward is not likely to generate significantly different results because the market only began 


\section{Table 6}

The Market's Response to Large and Small Federal Funds Rate Target Changes Accompanied by Discount Rate Changes

\begin{tabular}{|c|c|c|c|c|}
\hline Coefficient & $\mathrm{T3m}$ & $\mathrm{T} 12 \mathrm{~m}$ & $\mathrm{T10y}$ & T30y \\
\hline$\gamma$ & $\begin{array}{c}-0.0007 \\
(0.88)\end{array}$ & $\begin{array}{c}-0.0001 \\
(0.16)\end{array}$ & $\begin{array}{c}-0.0006 \\
(0.51)\end{array}$ & $\begin{array}{c}-0.0006 \\
(0.62)\end{array}$ \\
\hline$\delta$ & - & $\begin{array}{c}0.7472^{*} \\
(18.25)\end{array}$ & $\begin{array}{l}0.5828 * \\
(12.49)\end{array}$ & $\begin{array}{c}0.4453^{*} \\
(11.20)\end{array}$ \\
\hline$\mu_{\Delta \mathrm{dr} \lg }$ & $\begin{array}{l}0.3009 * \\
(3.91)\end{array}$ & $\begin{array}{c}-0.0149 \\
(0.25)\end{array}$ & $\begin{array}{c}-0.1410 * \\
(2.14)\end{array}$ & $\begin{array}{c}-0.1312^{*} \\
(2.18)\end{array}$ \\
\hline$\mu_{\Delta \mathrm{drsm}}$ & $\begin{array}{l}0.3650 * \\
(8.21)\end{array}$ & $\begin{array}{l}0.0765 \\
(1.13)\end{array}$ & $\begin{array}{c}-0.1128 * \\
(2.34)\end{array}$ & $\begin{array}{c}-0.1504 * \\
(2.76)\end{array}$ \\
\hline$\mu_{\mathrm{n} \Delta \mathrm{dr}}$ & $\begin{array}{l}0.3062 * \\
(4.34)\end{array}$ & $\begin{array}{l}0.0916 * \\
(2.23)\end{array}$ & $\begin{array}{c}-0.0589 \\
(0.90)\end{array}$ & $\begin{array}{c}-0.0447 \\
(0.79)\end{array}$ \\
\hline $\begin{array}{c}\text { F-statistic } \\
\mu_{\Delta \mathrm{drlg}}=\mu_{\mathrm{n} \Delta \mathrm{dr}}\end{array}$ & 0.0026 & 2.2378 & 0.8104 & 1.1288 \\
\hline s.e. & 0.0407 & 0.0360 & 0.0526 & 0.0480 \\
\hline Adj. $R^{2}$ & 0.0900 & 0.4466 & 0.1703 & 0.1249 \\
\hline
\end{tabular}

*Indicates statistical significance at the 5 percent level. Estimated with the Newey-West heteroskedastic autocorrelation consistent covariance estimates with a lag of 7 .

reacting to funds rate target changes during the late 1980s. Despite this limitation, the equation

$$
\begin{aligned}
\Delta \mathrm{i}_{\mathrm{t}} & =\gamma+\delta \Delta \mathrm{T} 3 \mathrm{~m}_{\mathrm{t}} \\
& +\mu_{\mathrm{nd}} \Delta \mathrm{fftar}_{\mathrm{t}}^{\mathrm{nd}} \\
& +\mu_{\mathrm{sd}} \Delta \mathrm{fftar}_{\mathrm{t}}^{\mathrm{sd}} \\
& +\varepsilon_{\mathrm{t}},
\end{aligned}
$$

is estimated. Target changes are partitioned into those that constitute a new direction for policy, $\Delta \mathrm{fftar}_{\mathrm{t}}^{\text {nd }}$ and those that are changes in the same direction, $\Delta$ fftar ${ }_{t}^{\text {sd }}$.

The results are presented in Table 7.

March of 1984 produces results that are less encouraging to the hypothesis- the response is larger when there is a change in the direction of policy. target changes direction; and the difference is statistically significant for all but T30y.

The fact that $\mu_{\text {nd }}$ is statistically insignificant for the 30-year rate suggests that the 30-year rate moved normally in response to a change in the 3-month T-bill rate. The 3month rate also responds more when there is a change in the direction of policy, but the difference is not statistically significant. In comparison, the 12-month and 10-year rates move significantly more when the target change marks a change in the direction of policy. These responses are consistent with the inflation-expectations interpretation for the lack of response of the long-term rates to target changes. Because rates tend to exhibit considerable persistence, i.e., moving up or down over long cycles, when rates first start to move up or down the market might believe that there will be a significant change in the real rate. This interpretation is particularly compelling for the 10-year rate because it responded significantly more than usual to a change in the 3-month T-bill rate. The observed larger responses of T12m and T10y may have led some market analysts to suggest that the market's reaction is larger when the direction of policy is changed. Because of the small number of direction changes over this sample period, however, caution is required. ${ }^{13}$

\section{CONCLUSIONS}

The purpose of this paper was to investigate several hypotheses concerning the market's reaction to changes in the Fed's funds rate target during the period between October 2, 1989, through December 31, 1997. Principal among these hypotheses is whether there is a difference in the reaction of short-term and long-term interest rates, which suggest that these actions cause the market to change its expectation for inflation. While response of the 10 -year and 30 -year Treasury rates to changes in the funds rate target was not statistically significant, the lack of response did mark a statistically significant departure from the usual relationship between these long-term rates and the 3-month T-bill rate. While no direct 
evidence is presented, I think it is reasonable to interpret the marked departure in the usual relationship between these rates as being due to a revision of the market's outlook for inflation. This is particularly true since statistical tests rule out the possibility that long-term rates simply do not respond significantly to changes in the funds rate target. M oreover, this interpretation is consistent with the finding that long-term rates respond as much (or more than) short-term rates to other real shocks, such as the employment report. If this interpretation is correct, the results suggest that the Fed has some credibility as an inflation fighter.

Further analysis, however, shows that nearly all of the significant departure in the relationship between long-term and short-term rates associated with target changes is due to the 12 target changes that were accompanied by a change in the discount rate. Hence, it is the discount rate that appears to matter most for the market's inflation outl ook. Once the change in the discount rate is accounted for, the size of the target change does not appear to be important in determining the market's reaction.

Finally, the reaction of all rates to a target change appears to be somewhat larger when the target change marks a change in the direction of policy. Interestingly, none of the changes in the direction of policy was accompanied by a discount rate change. The reader is cautioned, however, that the sample size on which this result is based is very small.

\section{REFERENCES:}

Campbell, John Y., Andrew W. Lo, and A. Craig MacKinlay. The Econometrics of Financial Markets, Princeton University Press, 1997. and Robert J. Shiller. "Yield Spreads and Interest Rate Movements: A Bird's Eye View," Review of Economic Studies (May 1991), pp. 495-514.

Cook, Timothy, and Thomas Hahn. "The Effect of Changes in the Federal Funds Rate Target on Market Interest Rates in the 1970's," Joumal of Monetary Economics (September 1989), pp. 331-51.

Feinman, Joshua N. "Estimating the Open Market Desk's Daily Reaction Function," Journal of Money, Credit and Banking (May 1993), pp. 23147.

\section{Table 7}

The Market's Response to Federal Funds Rate Target Changes When Policy Changes Direction

\begin{tabular}{|c|c|c|c|c|}
\hline Coefficient & T3m & $\mathrm{T} 12 \mathrm{~m}$ & T10y & T30y \\
\hline$\gamma$ & $\begin{array}{c}-0.0008 \\
(0.93)\end{array}$ & $\begin{array}{c}-0.0003 \\
(0.39)\end{array}$ & $\begin{array}{c}-0.0007 \\
(0.64)\end{array}$ & $\begin{array}{c}-0.0007 \\
(0.72)\end{array}$ \\
\hline$\delta$ & - & $\begin{array}{c}0.7468 * \\
(18.30)\end{array}$ & $\begin{array}{l}0.5818^{*} \\
(12.50)\end{array}$ & $\begin{array}{c}0.4445^{*} \\
(11.21)\end{array}$ \\
\hline$\mu_{\mathrm{nd}}$ & $\begin{array}{l}0.3744 * \\
(4.00)\end{array}$ & $\begin{array}{l}0.2149 * \\
(2.32)\end{array}$ & $\begin{array}{l}0.1838 * \\
(2.78)\end{array}$ & $\begin{array}{l}0.0617 \\
(1.42)\end{array}$ \\
\hline$\mu_{\mathrm{sd}}$ & $\begin{array}{l}0.3046 * \\
(5.77)\end{array}$ & $\begin{array}{l}0.0195 \\
(0.47)\end{array}$ & $\begin{array}{c}-0.1261^{*} \\
(2.70)\end{array}$ & $\begin{array}{c}-0.1119 * \\
(2.61)\end{array}$ \\
\hline $\begin{array}{c}\text { F-statistic } \\
\mu_{\text {nd }}=\mu_{\text {sd }}\end{array}$ & 0.4225 & $3.8189 *$ & $15.7301^{*}$ & $8.8317^{*}$ \\
\hline s.e. & 0.0407 & 0.0360 & 0.0525 & 0.0480 \\
\hline Adj. $R^{2}$ & 0.0903 & 0.4463 & 0.1724 & 0.1251 \\
\hline
\end{tabular}

Goodfriend, Marvin. "Interest Rate Policy and the Inflation Scare Problem: 1979-1992," Federal Reserve Bank of Richmond Economic Quarterly (Winter 1993), pp. 1-24. . "Interest Rates and the Conduct of Monetary Policy," Carnegie-Rochester Conference Series on Public Policy (Spring 1991), pp. 7-30.

Meulendyke, Ann-Marie. U. S. Monetary Policy \& Financial Markets, Federal Reserve Bank of New York, 1998.

Newey, Whitney K., and Kenneth D. West. "A Simple, Positive SemiDefinite, Heteroskedasticity and Autocorrelation Consistent Covariance Matrix," Econometrica (May 1987), pp. 703-08.

Robertson, John C., and Daniel L. Thornton. "Using Federal Funds Futures Rates to Predict Federal Reserve Actions," this Review (November/ December 1997), pp. 45-53.

Rudebusch, Glenn D. "Federal Reserve Interest Rate Targeting, Rational Expectations, and the Term Structure," Joumal of Monetary Economics (April 1995), pp. 245-74.

Shiller, Robert J., John Y. Campbell, and Kermit L. Schoenholtz. "Forward Rates and Future Policy: Interpreting the Term Structure of Interest Rates," Brookings Papers on Economic Activity (1983), pp. 173-217. 
Thornton, Daniel L. “Does the Fed's New Policy of Immediate Disclosure Affect the Market?" this Review (Novemberl December 1996),

pp. $77-88$.

"The Predictive Power of the T-Bill/ Federal Funds Rate Spread: Resolving the Anomalies at the Very Short End of the Term Structure." unpublished manuscript, Federal Reserve Bank of St. Louis (1998). 
The purpose of this appendix is to investigate whether the effect of a funds rate target change on the relationship between long-term and T-bill rates is due to a nonlinear relationship between changes in the T-bill and long-term rates. Specifically, long-term rates may not move proportionately with changes in the T-bill rate when there are large changes in the T-bill rate. Since large changes in the T-bill rate are likely to be associated with changes in the funds rate target, it is possible that the results are due to a fundamental nonlinear relationship between changes in the T-bill and long-term rates. To test for this possibility, large changes in the T-bill rate, $\Delta \mathrm{T} 3 \mathrm{~m}_{\mathrm{t}}^{\mathrm{L}}$, were identified. A change in the T-bill rate is considered large if it is more than two standard deviations of the daily change in the T-bill rate over the sample period.

$\mathrm{N}$ ext the equation

$$
\begin{aligned}
\Delta \mathrm{i}_{\mathrm{t}} & =\gamma+\delta \Delta \mathrm{T} 3 \mathrm{~m}_{\mathrm{t}} \\
& +\mu \Delta \mathrm{T} 3 \mathrm{~m}_{\mathrm{t}}^{\mathrm{L}}+\varepsilon_{\mathrm{t}}
\end{aligned}
$$

was estimated using both $\Delta \mathrm{T} 10 \mathrm{y}$ and $\Delta T 30 y$. If the relationship between the long-term rate and the T-bill rate is different when there are large changes in the T-bill rate, estimates of $\mu$ will be significantly different from zero. This equation was estimated during the period between August 11, 1987, through December 31, 1997, and during the period between October 6, 1982, through August 10, 1987. The latter period was used because the market did not respond significantly to target changes during this time frame.

Consequently, during this time, large changes in the T-bill rate definitely are not associated with changes in the funds rate target.

Estimates of Equation A.1 are presented in Table A.1. There were 91 large changes in the T-bill rate during the first period and 120 during the second. The results suggest no significant nonlinearity during either period. The estimate of $\mu$ was negative, but very small and not statistically significant.

The results for the first period could be affected by the fact that some of the large changes in the T-bill rate occurred when there was a change in the funds rate target. Hence, the effect of large changes in the T-bill rate is confounded with changes in the funds rate target. To separate these effects, the equation

$$
\begin{aligned}
\Delta \mathrm{i}_{\mathrm{t}} & =\gamma+\delta_{0} \Delta \mathrm{T} 3 \mathrm{~m}_{\mathrm{t}} \\
& +\delta_{1} \Delta \mathrm{T} 3 \mathrm{~m}_{\mathrm{t}}^{\mathrm{NTC}} \\
& +\delta_{2} \Delta \mathrm{T} 3 \mathrm{~m}_{\mathrm{t}}^{\top \mathrm{C}} \\
& +\varepsilon_{\mathrm{t}}
\end{aligned}
$$

was estimated, where $\Delta \mathrm{T} 3 \mathrm{~m}_{\mathrm{t}}^{\mathrm{NTC}}$ denotes large changes in the T-bill rate not accompanied by a target change, and $\Delta \mathrm{T} 3 \mathrm{~m}_{\mathrm{t}}^{\mathrm{TC}}$ denotes changes in the T-bill rate accompanied by a target change. If there is an essential nonlinear relationship between changes in long-term and T-bill rates, the estimate of $\delta_{1}$ should be negative and statistically significant. Moreover, if nonlinearity is responsible for the reaction of the longterm and T-bill rates to target changes, the hypothesis $\delta_{1}=\delta_{2}$ will not be rejected.

Estimates of Equation A.2 are presented in Table A.2. While the null hypothesis that $\delta_{1}=\delta_{2}$ is not rejected, the point estimates of $\delta_{2}$ are much larger in absolute value than the point estimates of $\delta_{1}$. Likewise, the estimates of $\delta_{1}$ are not significantly different from zero at the 5 percent level. These results suggest that the effect of a funds rate target change on the relationship between the long-term and T-bill rates is not due to nonlinearity in the relationship itself. Hence, it appears that the response of long-term rates is significantly different when the source of the shock is monetary policy. 


\section{RFYHEW}

NOVEMBER/ DECEMBER 1998

Table A. 1

Estimates of Equation A.1

\begin{tabular}{|c|c|c|c|c|}
\hline \multirow[b]{2}{*}{ Coefficient } & \multicolumn{2}{|c|}{$8 / 11 / 87-12 / 31 / 97$} & \multicolumn{2}{|c|}{$10 / 6 / 82-8 / 10 / 87$} \\
\hline & T10y & T30y & $\mathrm{T} 10 \mathrm{y}$ & $\mathrm{T} 30 \mathrm{y}$ \\
\hline$\gamma$ & $\begin{array}{c}-0.0010 \\
(0.92)\end{array}$ & $\begin{array}{c}-0.0010 \\
(1.04)\end{array}$ & $\begin{array}{c}-0.0011 \\
(0.49)\end{array}$ & $\begin{array}{c}-0.0013 \\
(0.60)\end{array}$ \\
\hline$\delta$ & $\begin{array}{c}0.5346^{*} \\
(15.37)\end{array}$ & $\begin{array}{c}0.4172^{*} \\
(13.58)\end{array}$ & $\begin{array}{c}0.6785 * \\
(14.12)\end{array}$ & $\begin{array}{c}0.5602^{*} \\
(12.58)\end{array}$ \\
\hline$\mu$ & $\begin{array}{c}-0.0857 \\
(1.11)\end{array}$ & $\begin{array}{c}-0.0540 \\
(0.71)\end{array}$ & $\begin{array}{c}-0.1277 \\
(1.63)\end{array}$ & $\begin{array}{c}-0.1057 \\
(1.45)\end{array}$ \\
\hline s.e. & 0.0557 & 0.0525 & 0.0730 & 0.0685 \\
\hline Adj. $R^{2}$ & 0.1889 & 0.1414 & 0.2932 & 0.2427 \\
\hline
\end{tabular}

*Indicates statistical significance at the 5 percent level.

Estimated with the Newey-West heteroskedastic autocorrelation consistent covariance estimates with a lag of 8 for the first period and with a lag of 6 for the second period.

\section{Table A.2}

\section{Estimates of Equation A.2}

\begin{tabular}{|c|c|c|}
\hline Coefficient & T10y & $\mathrm{T} 30 \mathrm{y}$ \\
\hline$\gamma$ & $\begin{array}{c}-0.0011 \\
(0.99)\end{array}$ & $\begin{array}{c}-0.0011 \\
(1.12)\end{array}$ \\
\hline$\delta_{0}$ & $\begin{array}{l}0.5575^{*} \\
(16.42)\end{array}$ & $\begin{array}{c}0.4363^{*} \\
(14.28)\end{array}$ \\
\hline$\delta_{1}$ & $\begin{array}{c}-0.0923 \\
(1.26)\end{array}$ & $\begin{array}{c}-0.0577 \\
(0.82)\end{array}$ \\
\hline$\delta_{2}$ & $\begin{array}{c}-0.2156^{*} \\
(2.45)\end{array}$ & $\begin{array}{c}-0.1876 \\
(2.35)\end{array}$ \\
\hline $\begin{array}{c}\text { F-statistic } \\
\delta_{1}=\delta_{2}\end{array}$ & 1.2802 & 1.6645 \\
\hline s.e. & 0.0557 & 0.0525 \\
\hline Adj. $R^{2}$ & 0.1905 & 0.1430 \\
\hline
\end{tabular}

*Indicates statistical significance at the 5 percent level. Estimated with the Newey-West heteroskedastic autocorrelation consistent covariance estimates with a lag of 8. 